\title{
A Rare Complication after TAVI: Acute Left Main Coronary Artery Occlusion and Successful Percutaneous Treatment
}

\author{
(1) Ömer Faruk Keskin1, (1) Mustafa Demir², (1) Atila İyisoy1
}

${ }^{1}$ Gülhane Training and Research Hospital, Clinic of Cardiology, Ankara, Turkey

2Tekden Private Hospital, Clinic of Cardiology, Denizli, Turkey

\begin{abstract}
Aortic valve stenosis is common in the elderly. Nowadays surgical aortic valve replacement has still been the gold standard of management, but many patients have been excluded from surgery given that they are very old, frail, or have comorbidities that increase operative risks. In the last decade, transcatheter aortic valve implantation (TAVI) has emerged as a new treatment option for these patients. Despite its being less invasive than surgery, TAVI has rare but fatal complications like vascular injuries. Vascular injuries
\end{abstract}

\section{Introduction}

Transcatheter aortic valve implantation (TAVI) is an alternative treatment to surgical aortic replacement in patients who have severe aortic stenosis and high are the most common complications after TAVI, and they range from dissection to perforation and acute thrombotic occlusion. We report a case of left main coronary artery occlusion following TAVI that caused cardiac arrest and was managed successfully with emergency percutaneous coronary intervention.

Keywords: Transcatheter aortic valve implantation (TAVI), percutaneous coronary intervention, left main occlusion

surgical risk ${ }^{(1)}$. Since its first description in 2002, it has been performed successfully in worldwide ${ }^{(2)}$. But despite its being less invasive than surgery, TAVI has rare but fatal complications like coronary obstruction. We report here a case of left main coronary artery (LMCA)

Address for Correspondence: Ömer Faruk Keskin, Gülhane Training and Research Hospital, Clinic of Cardiology, Ankara, Turkey e-mail: farukomerkeskin@gmail.com ORCID: orcid.org/0000-0002-4367-8589

Received: 12.05.2019 Accepted: 15.08.2019

Cite this article as: Keskin ÖF, Demir M, İyisoy A. A Rare Complication after TAVI: Acute Left Main Coronary Artery Occlusion and Successful Percutaneous Treatment.

EJCM 2019;7(3):156-159.

DOI: 10.32596/ejcm.galenos.2019.05.029

Presented in: Manuscript was submitted as an abstract and presented in 15th International Congress of Update in Cardiology and Cardiovascular Surgery by Prof. Dr. Atila İyisoy and it was asked from us to contribute to the E-Journal of Cardiovascular Medicine.

${ }^{\circ}$ Copyright 2019 by Heart and Health Foundation of Turkey (TÜSAV) / E Journal of Cardiovascular Medicine published by Galenos Publishing House. 
occlusion following TAVI that caused cardiac arrest and was managed successfully with emergency percutaneous coronary intervention (PCI).

\section{Case Report}

An 83-year-old male patient presented to our clinic with decompensated heart failure. He had hypertension, diabetes, and chronic obstructive pulmonary disease. On the physical examination, we found common rales in both lungs. Echocardiogram showed severe aortic stenosis (Pg Max/Mean=110/60 mmHg) and normal LV ejection fraction, 2-3. degree mitral regurgitation, 3. degree aortic regurgitation, and 2. degree tricuspid regurgitation. His systolic pulmonary artery pressure was $55 \mathrm{mmHg}$. After the stabilization of the patient, the risk scores were calculated for aortic surgery (Log. Euroscore was 21\%, Euroscore 2 was $14 \%$, STS score was $8,7 \%$ ) and the patient was accepted to have high surgical risk for surgery in our cardiology, cardiovascular surgery, and cardiac anesthesia joint committee. So, we decided to perform TAVI. The super-stiff wire was inserted into the left ventricle through the left Amplatz-2 catheter via left femoral artery. The delivery system was advanced and predilatation was performed by creating hypotension at the level of the aortic valve under high-speed pacemaker (Figure 1A). Then, $29 \mathrm{~mm}$ Edwards Sapien XT aortic valve level was adjusted and the valve was implanted using balloon under high-speed pacemaker (Figure 1B, 1C). Valve placement was performed without any complications. No complication was detected in the patient's aortography and the procedure was ended. While the femoral closure was going on, the patient's hemodynamic impaired and then the patient had cardiac arrest and was immediately intubated. Echocardiography showed no pericardial effusion. At fluoroscopy, bioprosthetic valve was in place. Coronary angiography was performed from the contralateral groin. There was no flow from the proximal left main coronary artery (Figure 1D). Then, under the CPR, a 0,014-inch guidewire was advanced into LAD and multiple balloon angioplasty was performed with a $2.5 \times 15$ and $3.0 \times 20 \mathrm{~mm}$ balloon (Figure 2A, 2B). A 3.5x25 mm Commander BMS was implanted from LMCA to LAD and TIMI 2 flow was provided both in LAD and CFX artery. Then, the patient's rhythm was achieved. (Figure 2C, 2D). The patient was taken to the intensive care unit. He was arrested again after 5 hours and the rhythm could not be achieved despite the CPR for 45 minutes and the patient was exitus.

\section{Discussion}

TAVI includes the insertion of a prosthetic valve into the stenotic aortic valve through a vascular access without the need for open heart surgery. Despite its widespread use and increasing experience of surgeons, TAVI has life-threatening complications especially vascular injuries. Complication rates differ with the experience of surgeon, the size of the device, the site of catheter access, as well as the use of pre-procedural screening. The coronary obstruction was first reported in 2006 by Webbs. The frequency of this complication ranges from $0 \%$ to $4 \%$ but the mean frequency has been reported as $1 \%$ in large studies ${ }^{(3-8)}$. Clinical manifestation of this

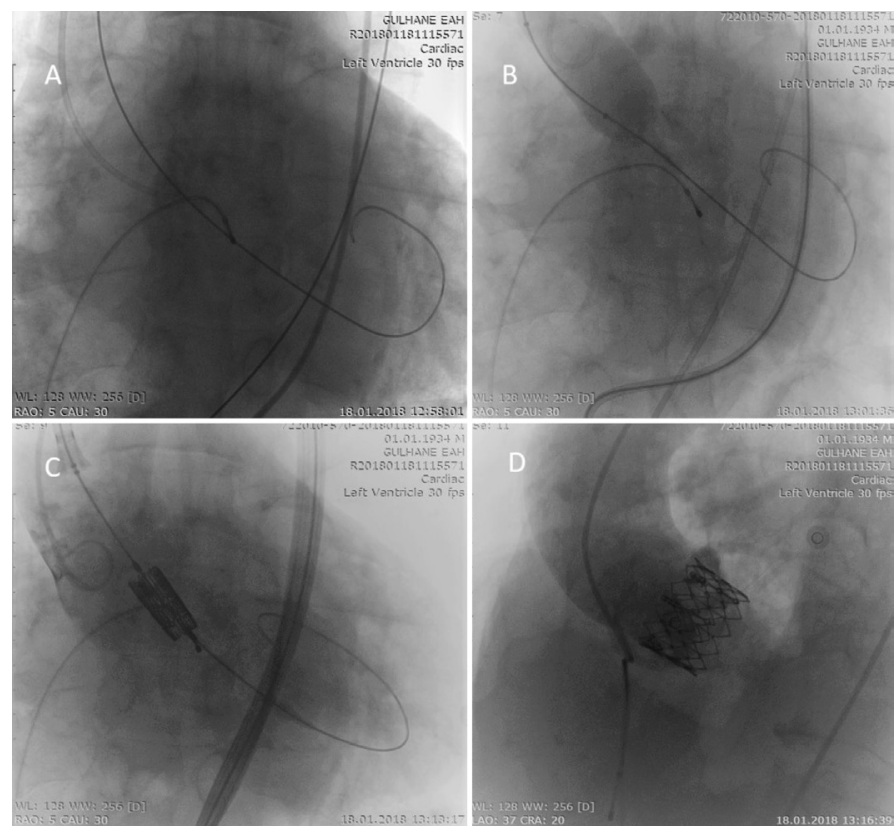

Figure 1. A. Predilatation was performed by creating hypotension under high-speed pacemaker. B. $29 \mathrm{~mm}$ Edwards Sapien XT aortic valve level was adjusted. C. $29 \mathrm{~mm}$ Edwards Sapien XT aortic valve was implanted using a balloon under a high-speed pacemaker. D. Coronary angiography showed total occlusion of the left main coronary artery 


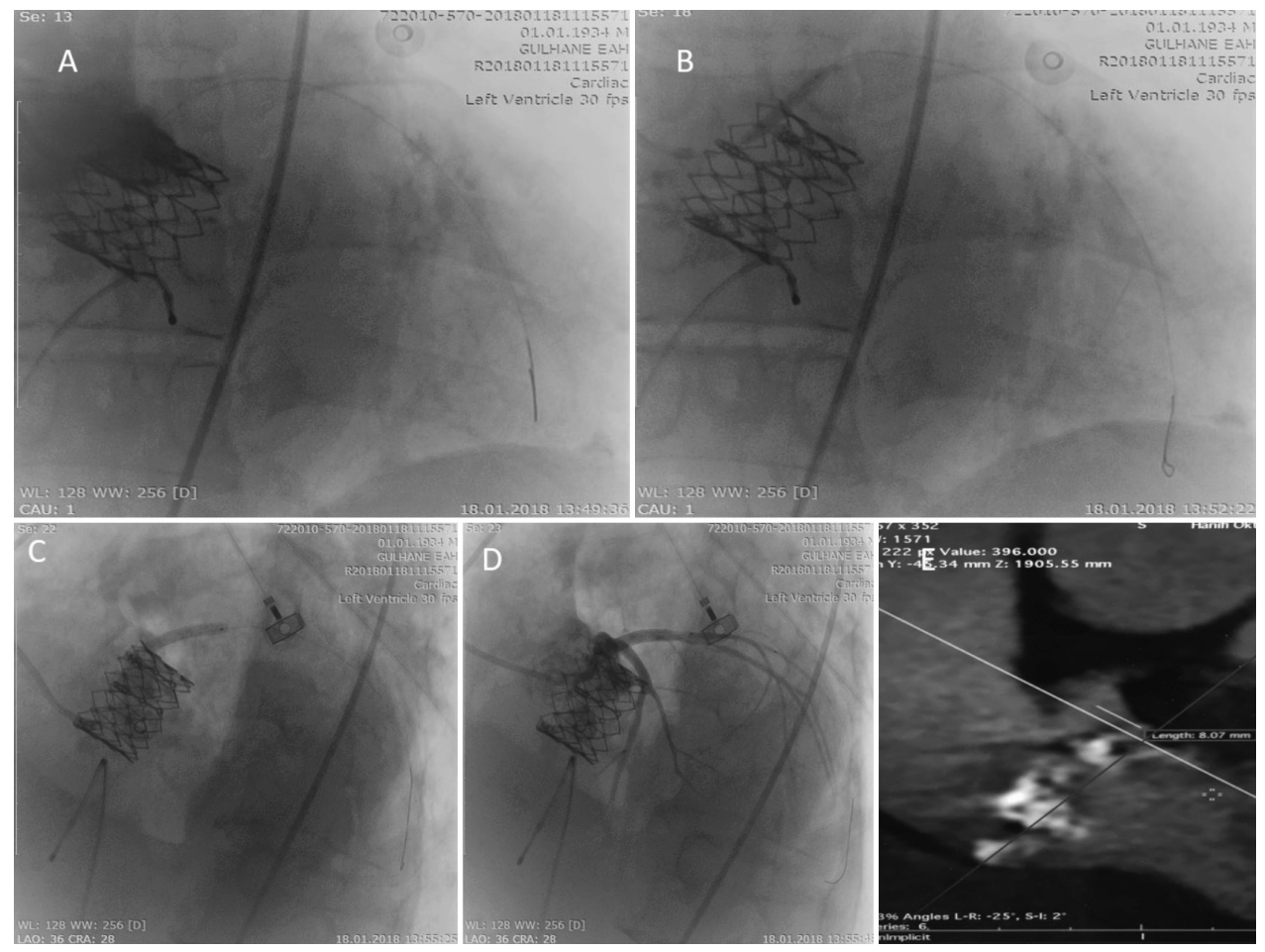

Figure 2. A. PTCA was performed with a $2.5 \times 15$ and $3.0 \times 20 \mathrm{~mm}$ balloons. B. $3.5 \times 25 \mathrm{~mm}$ Commander BMS was implanted from LMCA to LAD. C. After stent, TIMI 2 flow was provided both LAD and CFX. D. The distance between left coronary ostium and aortic annulus was $8.02 \mathrm{~mm}$

situation usually includes persistent hypotension, ST segment changes (elevation or depression), ventricular arrhythmias and sudden cardiac arrest immediately after valve implantation. ${ }^{6}$ The most known risk factors of this complication are shorter $(<10 \mathrm{~mm})$ distance between the left coronary ostium and aortic annulus, narrow aortic annulus, the presence of bulky calcium nodules on aortic leaflets, and use of balloon-expandable valve ${ }^{(6,9)}$. Coronary ostium height cut off level of $10 \mathrm{~mm}$ or shorter increases the risk of coronary obstruction ${ }^{(10)}$. Kapadia et al. ${ }^{(11)}$ recommended that a $0.014 \mathrm{~mm}$ guidewire can be advanced into LAD through a guiding catheter during valve deployment so that we can quickly access and if necessary dilate the left main trunk. In cases of severe hypotension, ST segment changes (elevation or depression), ventricular arrhythmias and sudden cardiac arrest, LMCA occlusion is the major complication apart from rupture. In such a situation, emergency angiography must be performed and coronary obstruction must immediately be treated with angioplasty and stenting. In failed percutaneous interventions, even coronary artery bypass (CABG) can also be performed and it may require Tandem Heart support ${ }^{(9,11,12)}$ Normally in our institution, we routinely take $\mathrm{CT}$ angiography before the TAVI procedure. In our case the distance between left coronary ostium and aortic annulus was $8.02 \mathrm{~mm}$ (Figure 2E). In our patient, we believe that shorter left coronary ostium height and bulky calcific nodule on aortic leaflet caused left main coronary occlusion. In a retrograde review, we did not advance a guidewire into LAD but we treated the patient successfully with stenting and after stenting the rhythm was achieved.

\section{Conclusion}

As a result, in situations following TAVI, such as severe hypotension, ST segment changes (elevation or depression), ventricular arrhythmias, and sudden cardiac, arrest emergency coronary angiography must be performed from the contralateral groin and LMCA occlusion must be 
treated with emergency angioplasty and stenting. In the TAVI procedure, a detailed preoperative evaluation is as important as the procedure.

\section{Ethics}

Informed Consent: The study was conducted in accordance with the international agreements and the Declaration of Helsinki, and informed consent for the study was taken from the patient's son.

\section{Authorship Contributions}

Surgical and Medical Practices: Ö.F.K., A.İ., Concept: M.D., Design: M.D., Data Collection or Processing: Ö.F.K., A.İ., Analysis or Interpretation: Ö.F.K., A.İ., Literature Search: Ö.F.K., M.D.,Writing: Ö.F.K.

Conflict of Interest: No conflict of interest was declared by the authors.

Financial Disclosure: The authors declared that this study received no financial support.

\section{References}

1. Baumgartner H, Falk V, Bax JJ, et al. 2017 ESC/EACTS Guidelines for the management of valvular heart disease. Eur Heart J 2017;38:2739-91.

2. Cribier A, Eltchaninoff $\mathrm{H}$, Bash A, et al. Percutaneous transcatheter implantation of an aortic valve prosthesis for calcific aortic stenosis: first human case description. Circulation 2002;106:3006-8.

3. Grube E, Schuler G, Buellesfeld L, et al. Percutaneous aortic valve replacement for severe aortic stenosis in high-risk patients using the secondand current third-generation self-expanding CoreValve prosthesis: device success and 30-day clinical outcome. Journal of the American College of Cardiology 2007;50:69-76.

4. Himbert D, Descoutures F, Al-Attar N, et al. Results of transfemoral or transapical aortic valve implantation following a uniform assessment in high-risk patients with aortic stenosis. Journal of the American College of Cardiology 2009;54:303-11.

5. Jilaihawi H, Chakravarty T, Weiss RE, et al. Meta-analysis of complications in aortic valve replacement: comparison of Medtronic-Corevalve, Edwards-Sapien and surgical aortic valve replacement in 8,536 patients. Catheterization and cardiovascular interventions: official journal of the Society for Cardiac Angiography \& Interventions 2012;80:128-38.

6. Ribeiro HB, Nombela-Franco L, Urena M, et al. Coronary obstruction following transcatheter aortic valve implantation: a systematic review. JACC Cardiovasc Interv 2013; 6:452-61.

7. Stabile E, Sorropago G, Cioppa A, et al. Acute left main obstructions following TAVI. EuroIntervention : journal of EuroPCR in collaboration with the Working Group on Interventional Cardiology of the European Society of Cardiology 2010;6:100-5.

8. Webb JG, Chandavimol M, Thompson CR, et al. Percutaneous aortic valve implantation retrograde from the femoral artery. Circulation 2006;113:84250 .

9. Ergene O, Emren V, Duygu H, et al. [A case of occurring hemodynamic deterioration and ST-segment elevation during transcatheter aortic valve implantation]. Turk Kardiyoloji Dernegi arsivi: Turk Kardiyoloji Derneginin yayin organidir 2014;42:556-9.

10. Holmes DR Jr, Mack MJ, Kaul S, et al. 2012 ACCF/AATS/SCAI/STS expert consensus document on transcatheter aortic valve replacement. Journal of the American College of Cardiology 2012;59:1200-54.

11. Kapadia SR, Svensson L, Tuzcu EM. Successful percutaneous management of left main trunk occlusion during percutaneous aortic valve replacement. Catheterization and cardiovascular interventions: official journal of the Society for Cardiac Angiography \& Interventions 2009;73:966-72.

12. Dagdelen S, Karabulut H, Alhan C. Acute left main coronary artery occlusion following TAVI and emergency solution. Anadolu kardiyoloji dergisi: AKD = the Anatolian journal of cardiology 2011;11:747-8. 